\title{
Using DEA and Grey Markovian Model to Measure the Goal Cost of Petroleum Enterprise
}

\author{
Jin-lan Liu, Meng-dong Wang, and Yin Bai \\ School of Management, Tianjin University, Tianjin 300072, China \\ liujinlan@tju.edu.cn, wma1104@yahoo.com.cn, baiyin@tju.edu.cn
}

\begin{abstract}
With the longstanding development of Chinese petroleum enterprises, the control of discovery and exploitation goal cost is becoming a essential problem. Data Envelopment Analysis (DEA) is a linear programming method for measuring the relative efficiency of decision making units where the presence of multiple inputs and outputs makes comparisons difficult. Grey Markovian model has the merits of both grey model and Markov transition probability matrix model. In this paper, DEA and Grey Markovian model are combined to measure the discovery and exploitation goal cost of petroleum enterprise. This method is applied to the cost analysis of Huabei Oil Company of PetroChina, which gives strong support to the feasibility and availability of the study in this paper.
\end{abstract}

Keywords: Petroleum Enterprise Discovery Goal Cost, Exploitation Goal Cost, Data Envelopment Analysis (DEA), Grey Markovian Model.

\section{Introduction}

Petroleum as a kind of non-renewable natural resource is crucial for the development of economy. However, in accordance with the gradual decrease of resource, the discovery and exploitation cost is rising. Cost management should be used to optimize benefits. Most of the enterprises especially those with long history start to focus on cost control in China. Therefore, the study on how to measure and predict the cost accurately for the petroleum enterprise is quite important.

Data Envelopment Analysis (DEA) is a nonparametric linear programmingbased method for measuring the relative efficiency of a decision making unit (DMU), which contains multiple inputs and multiple outputs [1]. The CCR model is the first DEA model and has been widely used in the frontier analysis. This model calculates the overall efficiency for each unit, where both technical efficiency and scale efficiency are aggregated into one value [2]. Grey Markovian model combining the grey model and Markov probability matrix model makes full use of historical data and improves the prediction accuracy of greatly fluctuating data sequences [3]. In this paper, we proposed a method to measure discovery and exploitation goal cost of petroleum enterprise by using DEA and Grey Markovian 
model. Goal cost prediction of the Huabei Oil Company was taken to illustrate the proposed model.

\section{Measuring Discovery and Exploitation Goal Cost}

According to the principles of DEA and Grey Markovian model with taking into account the characteristics of the petroleum enterprise's operation style, the discovery and exploitation goal cost can be measured through following steps.

\subsection{Calculating the Discovery and Exploitation Goal Cost Coefficients}

We postulate that $X_{i}$ is the discovery cost of the $i$ th year; $Y_{i}$ is the exploitation cost of the $i$ th year; $Q_{i}$ is the proved reserve of the $i$ th year; $W_{i}$ is the crude oil output of the $i$ th year. we can evaluate the relative efficiencies of the discovery and exploitation cost first by using the CCR model of DEA,. Then $X_{i}$ and $Y_{j}$ are separately arranged in descending sequence according to their coefficients of relative efficiency and we can get two data sequences: $\left\{X_{j}\right\}$ and $\left\{Y_{j}\right\}$.

The discovery goal cost coefficient:

$$
V_{1}=\sum_{j=1}^{n / 2} X_{j} / \sum_{j=1}^{n / 2} Q_{j} .
$$

The exploitation goal cost coefficient:

$$
V_{2}=\sum_{j=1}^{n / 2} Y_{j} / \sum_{j=1}^{n / 2} W_{j} .
$$

Where in (1) and (2), if $\mathrm{n}$ is an odd number, let $\mathrm{n}=\mathrm{n}+1$.

\subsection{Forecasting the Proved Reserve and the Crude Oil Output}

Grey Markovian model constructing process can be divided into three steps. First, with $\mathrm{GM}(1,1)$ model utilized, the stimulant sequence $X(k)$ and forecasting values can be got on the basis of the original data sequence. Then $X(k)$ is considered as the benchmark and divide the state into several areas with different curves paralleling to $X(k)$. Each area represents one state. Finally, through studying the state transition probability matrix, we can decide the grey area of the forecasting value and regard the midpoint of it as the most possible predictive value. Following the steps above, we can forecast the proved reserve $Q^{*}$ and the crude oil output $W^{*}$. 


\subsection{Measuring the Discovery and Exploitation Goal Cost}

Annual discovery goal cost:

$$
X^{*}=V_{1} * Q^{*}
$$

Annual exploitation goal cost:

$$
Y^{*}=V_{2} * W^{*} .
$$

\section{Illustrative Example}

Huabei Oil Company of PetroChina has a long exploitation history. The decrease of oil production and the increase of cost result in the reduction of its profit year after year. The method mentioned above was applied to predict the goal cost of Huabei Oil Company.

We arrange the discovery cost of the $i$ th year $\left(X_{i}\right)$ from Table 1 in descending sequence according to its coefficients of relative efficiency shown in Table 2. The same method is used to arrange the exploitation cost of the $i$ th year $\left(Y_{i}\right)$. According to formula (1) and (2), the discovery goal cost coefficient $\left(V_{1}\right)$ is 54.61 yuan/ton and the exploitation goal cost coefficient $\left(V_{2}\right)$ is 730.00 yuan/ton.

From the result shown in Table 3 and through analyzing the state transition probability matrix, the forecasting value of proved reserve in $2006\left(Q^{*}\right)$ is 2350.22 (10,000-ton). In the same way, the forecasting result of crude oil output in 2006 $\left(W^{*}\right)$ is 468.14 (10,000-ton). According to formula (3) and (4), the discovery goal cost $\left(X^{*}\right)$ and exploitation goal cost $\left(Y^{*}\right)$ in 2006 can be predicted as 128345.51 $(10,000$-yuan) and 341742.20 (10,000-yuan) respectively.

Table 1. Historical Data

\begin{tabular}{ccccccc}
\hline Year & $\begin{array}{c}\text { Discovery Cost } \\
(10,000 \text {-yuan })\end{array}$ & $\begin{array}{c}\text { Exploitation } \\
\text { input } \\
(10,000- \\
\text { yuan })\end{array}$ & $\begin{array}{c}\text { Proved } \\
\text { Reserve } \\
(10,000- \\
\text { ton })\end{array}$ & $\begin{array}{c}\text { Exploitation } \\
\text { Cost } \\
(10,000- \\
\text { yuan })\end{array}$ & Oil wells & $\begin{array}{c}\text { Crude Oil } \\
\text { Output } \\
(10,000- \\
\text { ton })\end{array}$ \\
\hline 1998 & $133,748.0$ & 34,563 & 2,900 & 344,246 & 1,598 & 469 \\
1999 & $139,278.0$ & 35,245 & 2,780 & 340,112 & 1,780 & 464 \\
2000 & $134,674.5$ & 35,928 & 2,531 & 339,915 & 1,962 & 465 \\
2001 & $167,764.6$ & 36,521 & 2,858 & 340,180 & 2,161 & 466 \\
2002 & $170,772.0$ & 37,472 & 2,660 & 340,443 & 2,291 & 467 \\
2003 & $208,570.3$ & 37,886 & 2,436 & 340,236 & 2,525 & 468 \\
2004 & $196,494.4$ & 37,924 & 2,540 & 345,290 & 2,600 & 473 \\
2005 & $203,427.3$ & 38,041 & 2,513 & 341,112 & 2,836 & 466 \\
\hline
\end{tabular}


Table 2. DEA Relative Efficiencies of Discovery Goal Cost

\begin{tabular}{cccc}
\hline Number & DMU & $\theta^{0}$ & Results of Evaluation \\
\hline 1 & 1998 & 1.0000 & efficient \\
2 & 1999 & 0.9401 & inefficient \\
3 & 2000 & 0.8396 & inefficient \\
4 & 2001 & 0.9327 & inefficient \\
5 & 2002 & 0.8460 & inefficient \\
6 & 2003 & 0.7663 & inefficient \\
7 & 2004 & 0.7982 & inefficient \\
8 & 2005 & 0.7873 & inefficient \\
\hline
\end{tabular}

Table 3. Fitted Result of the Proved Reserve

\begin{tabular}{ccc}
\hline Year & Original Value & Fitted Value \\
\hline 1999 & 2780 & 2747.51 \\
2000 & 2531 & 2702.75 \\
2001 & 2858 & 2658.71 \\
2002 & 2660 & 2615.39 \\
2003 & 2436 & 2572.78 \\
2004 & 2540 & 2530.86 \\
2005 & 2513 & 2489.63 \\
\hline
\end{tabular}

\section{Conclusion}

Based on the DEA and Grey Markovian model, a forecasting model of discovery and exploitation goal cost in petroleum enterprise has been set up. From the predicting result of Huabei Oil Company, this model is convenient to apply in practice.

\section{References}

1. Nevera Stancheva, Vyara Angelova.: Measuring the Efficiency of University Libararies Using Data Envelopment Analysis. $10^{\text {th }}$ Conference on Professional Information Resources (2004)

2. R. D. Banker, A. Charnes, W. W. Cooper. Some models for estimating technical and scale efficiencies in data envelopment analysis. Management Science, 30(9), (1984) 1078-1092

3. He Yong, Bao Yidan. Grey-Markov Forecasting Model and its Application. Systems Engineering Theory and Practice (1992)

4. A. Charnes, W. W. Cooper, E. Rhodes. Measuring the efficiency of decision making units European Journal of Operations Research, 2(6), (1978) 429-444

5. Sun Jihu. Forecasting Model of Coal Requirement Quantity Based on Grey System Theory. Journal of China University of Mining \& Technology, 11(2), (2001) 192-195 